\title{
Synthesis of Fe-Doped ZnO Nanorods by Rapid Mixing Hydrothermal Method and Its Application for High Performance UV Photodetector
}

\author{
Chan Oeurn Chey, ${ }^{1}$ Ansar Masood, ${ }^{2}$ A. Riazanova, ${ }^{2}$ Xianjie Liu, ${ }^{3}$ K. V. Rao, ${ }^{2}$ \\ Omer Nur, ${ }^{1}$ and Magnus Willander ${ }^{1}$ \\ ${ }^{1}$ Department of Science and Technology, Linköping University, 60174 Norrköping, Sweden \\ ${ }^{2}$ Department of Materials Science, Royal Institute of Technology, 10044 Stockholm, Sweden \\ ${ }^{3}$ Department of Physics, Chemistry and Biology, Linköping University, 88183 Linköping, Sweden \\ Correspondence should be addressed to Chan Oeurn Chey; chan.oeurn.chey@liu.se
}

Received 4 July 2014; Revised 16 September 2014; Accepted 11 October 2014; Published 6 November 2014

Academic Editor: Fathallah Karimzadeh

Copyright (C) 2014 Chan Oeurn Chey et al. This is an open access article distributed under the Creative Commons Attribution License, which permits unrestricted use, distribution, and reproduction in any medium, provided the original work is properly cited.

\begin{abstract}
We have successfully synthesized Fe-doped $\mathrm{ZnO}$ nanorods by a new and simple method in which the adopted approach is by using ammonia as a continuous source of $\mathrm{OH}^{-}$for hydrolysis instead of hexamethylenetetramine (HMT). The energy dispersive X-ray (EDX) spectra revealed that the Fe peaks were presented in the grown Fe-doped $\mathrm{ZnO}$ nanorods samples and the X-ray photoelectron spectroscopy (XPS) results suggested that $\mathrm{Fe}^{3+}$ is incorporated into the $\mathrm{ZnO}$ lattice. Structural characterization indicated that the $\mathrm{Fe}$-doped $\mathrm{ZnO}$ nanorods grow along the $c$-axis with a hexagonal wurtzite structure and have single crystalline nature without any secondary phases or clusters of $\mathrm{FeO}$ or $\mathrm{Fe}_{3} \mathrm{O}_{4}$ observed in the samples. The Fe-doped $\mathrm{ZnO}$ nanorods showed room temperature $(300 \mathrm{~K})$ ferromagnetic magnetization versus field $(\mathrm{M}-\mathrm{H})$ hysteresis and the magnetization increases from $2.5 \mu \mathrm{emu}$ to $9.1 \mu \mathrm{emu}$ for $\mathrm{Zn}_{0.99} \mathrm{Fe}_{0.01} \mathrm{O}$ and $\mathrm{Zn}_{0.95} \mathrm{Fe}_{0.05} \mathrm{O}$, respectively. Moreover, the fabricated $\mathrm{Au} / \mathrm{Fe}$-doped $\mathrm{ZnO}$ Schottky diode based UV photodetector achieved $2.33 \mathrm{~A} / \mathrm{W}$ of responsivity and $5 \mathrm{~s}$ of time response. Compared to other $\mathrm{Au} / \mathrm{ZnO}$ nanorods Schottky devices, the presented responsivity is an improvement by a factor of 3.9.
\end{abstract}

\section{Introduction}

Diluted transition metals (TMs) doped $\mathrm{ZnO}$ nanomaterials result in changing of the structural, electrical, magnetic, and optical properties of $\mathrm{ZnO}$ nanostructures. Transition metal doped $\mathrm{ZnO}$ especially is promising material as a room temperature ferromagnetic diluted magnetic semiconductors. Therefore, TMs doped $\mathrm{ZnO}$ nanomaterials are of interest in many current and future applications such as nanoelectronics, optoelectronics, photonic devices, spin electronics applications, and sensor devices, for example, spin-based lightemitting diodes, UV sensors, spin transistors, nonvolatile memory, and ultrafast optical switches [1-7]. Among the TMs doped $\mathrm{ZnO}$ nanomaterials, Fe-doped $\mathrm{ZnO}$ nanorods are of great potential in many applications due to the excellent electronic, magnetic, and optical properties [8]. The doping of semiconductor materials prepared by different methods or by the same method but different preparation processes usually shows different properties. New device applications of Fedoped $\mathrm{ZnO}$ nanomaterials have attracted many researchers to synthetize this material using many different physical and chemical methods. Many methods have been used to synthesize Fe-doped $\mathrm{ZnO}$ nanomaterial with different morphologies which has been published in the literature. To mention some, Fe-doped $\mathrm{ZnO}$ nanoparticles were prepared by the coprecipitation method [9-11], while Fe-doped $\mathrm{ZnO}$ powders and $\mathrm{Fe}$-doped $\mathrm{ZnO}$ nanorods array have been synthesized via other high temperature methods $[12,13]$; Fe-doped $\mathrm{ZnO}$ thin films were deposited by sputtering and spin coated methods [14-23], and Fe-doped $\mathrm{ZnO}$ nanorods were grown 
by the hydrothermal methods [24-27]. Among the different growth methods, the hydrothermal methods are favorable, friendly, and attractive due to simplicity, low cost, being less hazardous, scale-up possibility, and they are performed at low temperature (lower than $100^{\circ} \mathrm{C}$ ). Furthermore, the latest property is advantageous since it can be used to grow $\mathrm{ZnO}$ nanostructures on flexible and foldable substrates. Moreover, the morphology and properties of $\mathrm{ZnO}$ nanostructures can be controlled by varying the growth conditions such as the temperature, growth time, precursor concentration, and the $\mathrm{pH}$ of the growth solution [28, 29].

In this work, Fe-doped $\mathrm{ZnO}$ nanorods were synthesized by a modified preparation procedure using the low temperature hydrothermal approach. The Fe-doped $\mathrm{ZnO}$ nanorods growth developed here represents a new and simple method which adopted approach by using ammonia as a continuous source of $\mathrm{OH}^{-}$for hydrolysis during the growth instead of hexamethylenetetramine (HMT). Morphology, chemical composition, and structural and room temperature magnetic properties of the Fe-doped $\mathrm{ZnO}$ have been investigated. Finally, a simple $\mathrm{Au} / \mathrm{Fe}$-doped $\mathrm{ZnO}$ Schottky diode based UV photodetector was fabricated and IV characteristic and timedependent photoresponse have been conducted under on/off UV illuminations. The performance of the UV photodetector based $\mathrm{Au} / \mathrm{Fe}$-doped $\mathrm{ZnO}$ nanorods Schottky diode with large detection area $\left(1 \mathrm{~cm}^{2}\right)$ has been studied.

\section{Experiment Procedure}

2.1. Growth of Fe-Doped $\mathrm{ZnO}$ Nanorods. Zinc nitrate hexahydrate $\left(\mathrm{ZnNO}_{3} \cdot 6 \mathrm{H}_{2} \mathrm{O}\right)$, iron (II) chloride tetrahydrate $\left(\mathrm{FeCl}_{2} \cdot 4 \mathrm{H}_{2} \mathrm{O}\right)$, and iron (III) chloride hexahydrate $\left(\mathrm{FeCl}_{3} \cdot 6 \mathrm{H}_{2} \mathrm{O}\right)$ were used as precursors. All chemicals were purchased from Sigma Aldrich and were used without further purification. The growth solution was prepared by the mixing of $0.075 \mathrm{M}$ of zinc nitrate hexahydrate anda specific concentration of the iron source prepared by Iron (II) chloride tetrahydrate and Iron (III) chloride hexahydrate with the ratio $\left(\left[\mathrm{Fe}^{+2}\right]:\left[\mathrm{Fe}^{+3}\right]=1: 2\right)$ in deionized water. Then the growth solution was subsequently stirred with a magnetic stirrer at room temperature for one hour and then ammonia solution is added dropwise to the growth solution at room temperature, resulting in an orange solution with a $\mathrm{pH}=9.3$. This solution was kept under magnetic stirring for one hour at room temperature. The substrates were cleaned with isopropanol in an ultrasonic bath and then spin coated three times with a seed solution containing zinc acetate at $2500 \mathrm{rpm}$ for $30 \mathrm{~s}$; then the samples were annealed at $120^{\circ} \mathrm{C}$ for 10 minutes. Finally, the substrates were placed horizontally in the growth solution and kept in a preheated oven at $90^{\circ} \mathrm{C}$ for 6 hours. After the growth duration is completed, the samples were collected and washed with deionized water and dried at room temperature for further characterization. We believe that synthesis of high quality of Fe-doped $\mathrm{ZnO}$ nanorods can be useful for nanotechnology applications. In this adopted approach, ammonia was used to tailor $\mathrm{pH}$ of the growth solution and to facilitate $\mathrm{ZnO}$ nanocrystals growth. Ammonia reacts

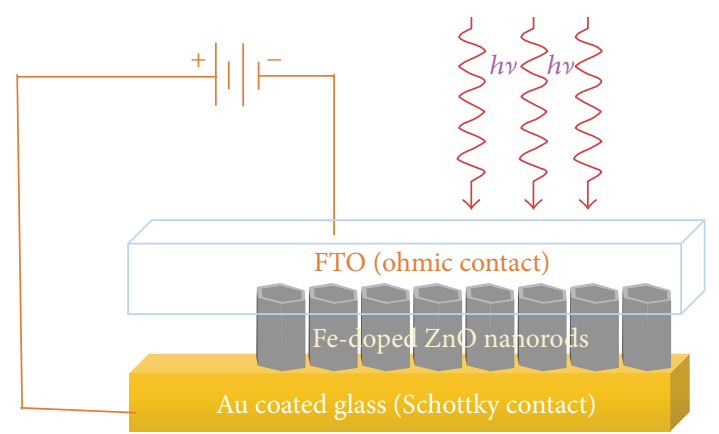

FIGURE 1: Schematic diagram of simple photodetector based on large area $\mathrm{Au} / \mathrm{Fe}$-doped $\mathrm{ZnO}$ nanorods/FTO Schottky diode.

with water to provide continuous source of $\mathrm{OH}^{-}$required for hydrolysis and aid precipitation of final products. Furthermore, ammonia can generate a large amount of zinc ammine complexes immediately in the solution and these complexes are absorbed on the six side planes of $\mathrm{ZnO}$ nanorods, which can facilitate the growth of $\mathrm{ZnO}$ nanorods structure by slowing down the growth velocity of the side surfaces [30]. By increasing the ammonia content in the growth solution, the nuclei of $\mathrm{ZnO}$ nanocrystals can rapidly form on the substrates, which produces dense and long $\mathrm{ZnO}$ nanorods over a large area [31, 32]. Therefore, high ammonia contents as additive to hydrolyze in the growth solution provide $\mathrm{Fe}$ ions doped in $\mathrm{ZnO}$ nanorods without morphology deformation.

2.2. Characterization Process. The field emission scanning electron microscope (FESEM), EDX, XPS, and XRD are used to characterize the surface morphology, chemical composition, and crystal structural of the grown samples, while the room temperature ferromagnetic properties were investigated by superconducting quantum interference device (SQUID) measurements.

2.3. Device Fabrication Process. For the fabrication of the $\mathrm{Au} / \mathrm{Fe}$-doped $\mathrm{ZnO}$ nanorods UV photodetector, transparent FTO film was taped on the top of the Fe-doped $\mathrm{ZnO}$ nanorods grown on gold coated glass substrate. The schematic diagram of the simple UV photodetector based on large area $\mathrm{Au} / \mathrm{ZnO}$ nanorods/FTO Schottky diode is shown in Figure 1. In a UV photodetector, large Schottky barrier height at metal semiconductor interface results in improved responsivity and improved photocurrent to dark current ratio [33,34]. Therefore, Au with high work function was used to form a large Schottky barrier height on Fe-doped $\mathrm{ZnO}$ nanorods. The conducting FTO film was used as the ohmic contact due to its transparency and it also provides almost ideal ohmic contact with $n-\mathrm{ZnO}$ [35]. The current-voltage (I-V) curves of the fabricated diodes under dark and under UV illumination were measured by Agilent 4155B Semiconductor Parameter Analyzer. In this experiment, a constant UV illumination of $2 \mathrm{~mW} / \mathrm{cm}^{2}$ emitting at $365 \mathrm{~nm}$ was used as the excitation source. 


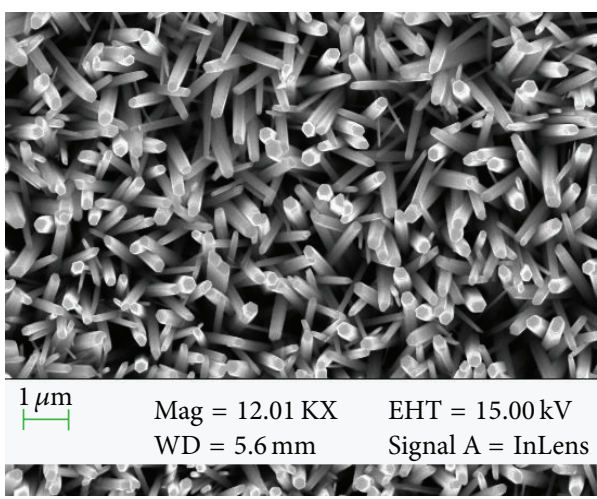

(a)

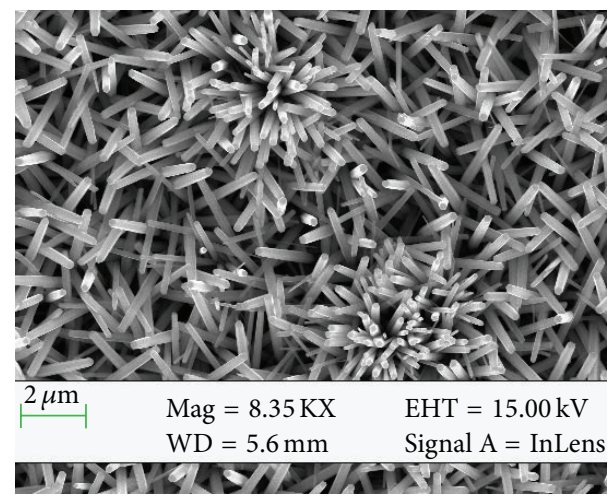

(b)

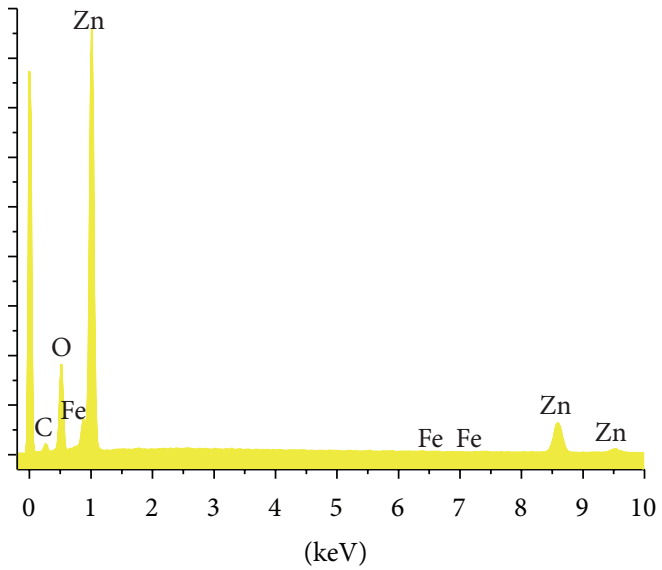

(c)

FIgure 2: (a) The SEM image of $\mathrm{Zn}_{0.99} \mathrm{Fe}_{0.01} \mathrm{O}$ nanorods. (b) The SEM image of $\mathrm{Zn}_{0.95} \mathrm{Fe}_{0.05} \mathrm{O}$ nanorods. (c) EDX spectrum of $\mathrm{Zn}_{0.99} \mathrm{Fe}_{0.01} \mathrm{O}$.

\section{Results and Discussion}

3.1. Morphology and Chemicals Composition. The surface morphology of the grown Fe-doped $\mathrm{ZnO}$ nanorods under different doping concentration has been performed by using SEM. Figures 2(a) and 2(b) show the SEM images of the $1 \%$ and $5.0 \%$ Fe-doped $\mathrm{ZnO}$ nanorods, respectively. The Fedoped $\mathrm{ZnO}$ nanorods have hexagonal shapes with diameters varying between 100 and $300 \mathrm{~nm}$. The chemical composition of the grown $\mathrm{Zn}_{0.99} \mathrm{Fe}_{0.01} \mathrm{O}$ was measured by using EDX which is shown in Figure 2(c). The EDX data revealed that the Fe's peaks were at $0.705 \mathrm{keV}, 6.404 \mathrm{keV}$, and $7.058 \mathrm{keV}$. This indicates the $\mathrm{Fe}$ ions were presented in the Fe-doped $\mathrm{ZnO}$ nanorods samples.

In order to verify the substitutions of the Fe ions in the $\mathrm{Zn}_{1-x} \mathrm{Fe}_{x} \mathrm{O}$ nanorods, XPS measurements were performed. Figure 3(a) shows the XPS spectra of $\mathrm{O}$ 1s peaks of both $\mathrm{ZnO}$ nanorods and $\mathrm{Fe}$-doped $\mathrm{ZnO}$ nanorods. For $\mathrm{ZnO}$ nanorods, the $\mathrm{O}$ 1s spectrum centered at 530.9 which belongs to $\mathrm{O}^{2-}$ in the wurtzite structure of a $\mathrm{ZnO}$ monocrystal and at $532.3 \mathrm{eV}$ is attributed to the presence of loosely bound oxygen on the surface $[15,17]$. In Fe-doped $\mathrm{ZnO}$ nanorods, the XPS spectra of the $\mathrm{O}^{2-}$ were slightly shifted to the higher binding energy value and the shoulder peaks are broader in comparison to the pure $\mathrm{ZnO}$ nanorods. This result indicates that the Fe ions indeed influence the optical properties of the $\mathrm{ZnO}$ nanorods. The chemical shift of the $\mathrm{O}$ 1s of the doped $\mathrm{ZnO}$ has also been revealed in the previous works $[22,27]$. As we know, the binding energy of $\mathrm{Fe} 2 \mathrm{p}$ signals was between 700 and $740 \mathrm{eV}$ and some of $\mathrm{Zn}$ Auger peaks are also presented in this region. Therefore, the XPS measurements were conducted for both $\mathrm{ZnO}$ nanorods and $\mathrm{Zn}_{1-x} \mathrm{Fe}_{x} \mathrm{O}$ nanorods. As it is known, the $\mathrm{FeO}$ has a peak position of $\mathrm{Fe} 2 \mathrm{p}_{1 / 2}$ at $722.3 \mathrm{eV}$ and $\mathrm{Fe} 2 \mathrm{p}_{3 / 2}$ at $709.3 \mathrm{eV}$ and $\mathrm{Fe}_{2} \mathrm{O}_{3}$ at $724.9 \mathrm{eV}$ and at $710.5 \mathrm{eV}$, respectively. In this study, the XPS signals at binding energy from $695 \mathrm{eV}$ to $735 \mathrm{eV}$ for pure $\mathrm{ZnO}$ and $\mathrm{Fe}$-doped $\mathrm{ZnO}$ are shown in Figure 3(b). From this figure, the Fe related signal in the $\mathrm{Zn}_{0.99} \mathrm{Fe}_{0.01} \mathrm{O}$ nanorods is not resolved from the $\mathrm{Zn}$ Auger because it is relatively small. This is a very similar case for the $\mathrm{Fe}$-doped $\mathrm{ZnO}$ in the previous works $[20,26]$. However, the Fe $2 \mathrm{p}$ core level photoemission spectrum for $\mathrm{Zn}_{0.95} \mathrm{Fe}_{0.05} \mathrm{O}$ nanorods is clearly observed, from which $\mathrm{Fe} 2 \mathrm{p}_{1 / 2}$ and $\mathrm{Fe}$ $2 \mathrm{p}_{3 / 2}$ peaks located at 725.47 and $711.7 \mathrm{eV}$ can be found. These Fe $2 \mathrm{p}$ peak positions are almost the same as values which have been reported in many previous works [15, 17, 19-24, 26, 27]. These obtained binding energies are larger than $\mathrm{Fe}^{3+}$; it is suggested that $\mathrm{Fe}$ is incorporated into the $\mathrm{ZnO}$ lattice in a state close to $\mathrm{Fe}^{3+}$. Furthermore, the investigated spectra of $\mathrm{Fe}$ $2 \mathrm{p}$ showed that the spin-orbit split energy difference between $\mathrm{Fe} 2 \mathrm{p}_{1 / 2}$ and $\mathrm{Fe} 2 \mathrm{p}_{3 / 2}$ is $13.77 \mathrm{eV}$. These results suggested that 

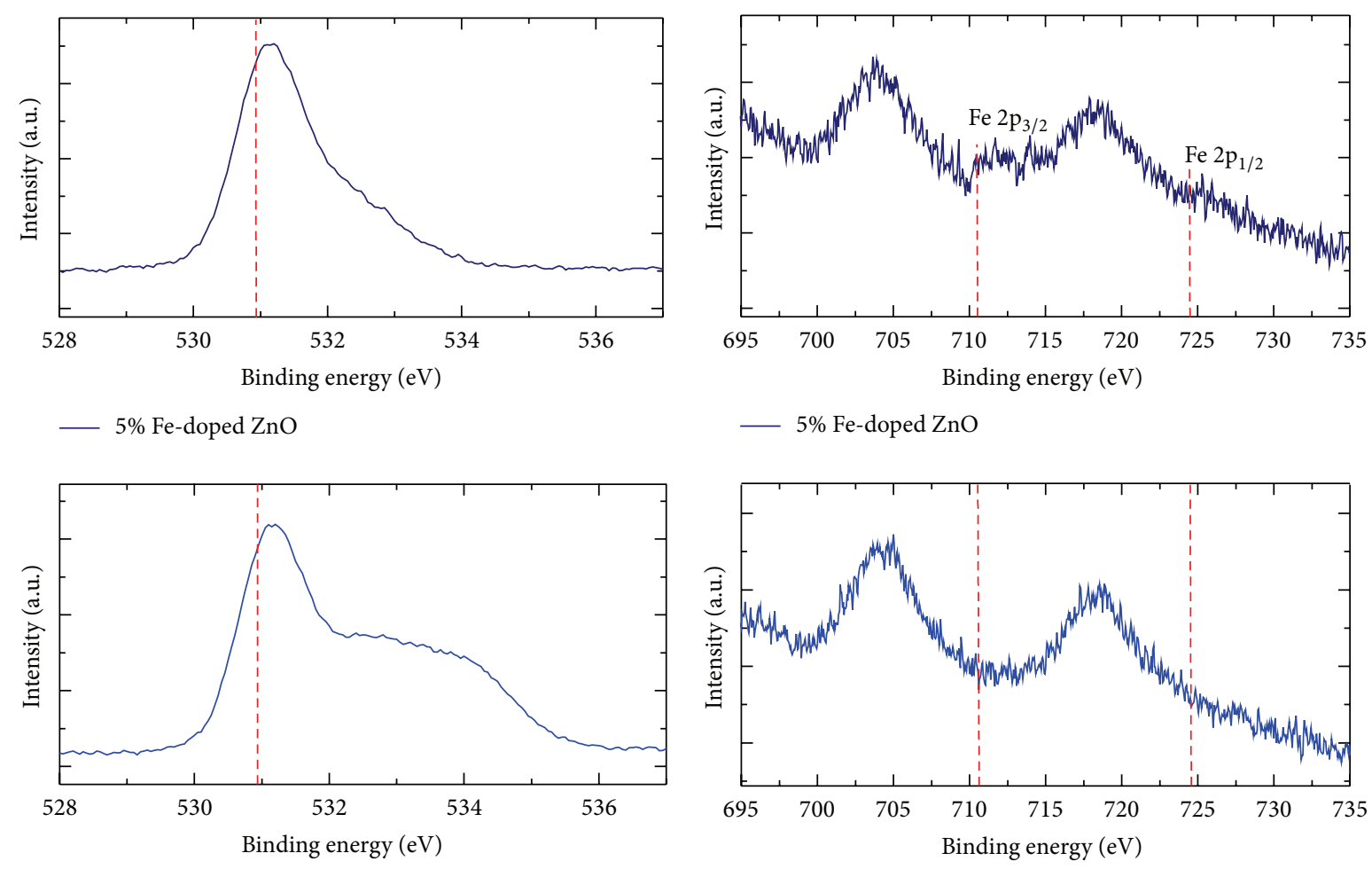

- $1 \% \mathrm{Fe}$-doped $\mathrm{ZnO}$

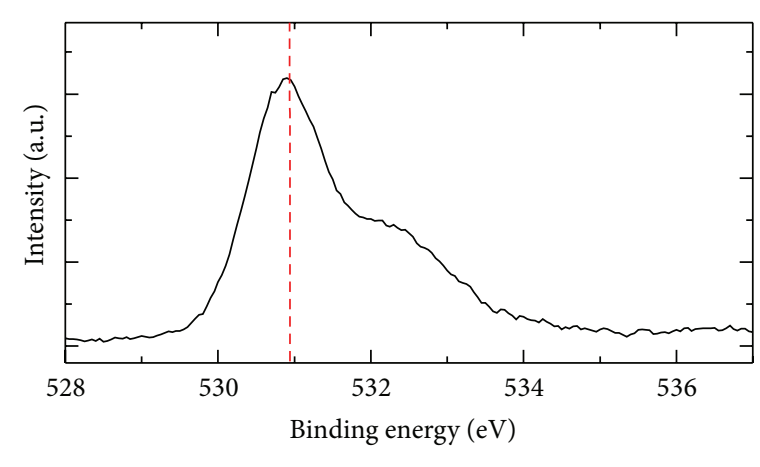

— Pure $\mathrm{ZnO}$

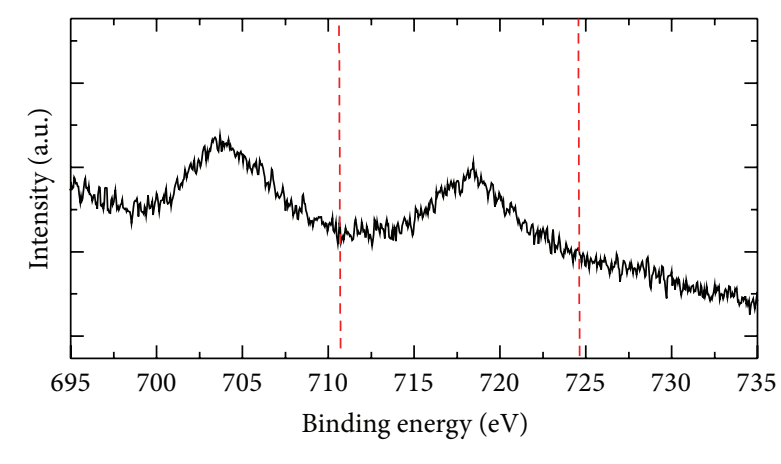

— Zn Auger from $\mathrm{ZnO}$

(a)

(b)

FIgURE 3: XPS spectra of (a) O 1s for $\mathrm{ZnO}$ and Fe-doped $\mathrm{ZnO}$ and (b) $\mathrm{Zn}$ Auger from $\mathrm{ZnO}$ and Fe 2p Fe-doped $\mathrm{ZnO}$.

there is no possibility of existence of $\mathrm{Fe}^{2+}$ or $\mathrm{Fe}^{0}$ in the samples because the energy difference of metallic ion and the $\mathrm{FeO}$ should be $13.10 \mathrm{eV}$ and $13.4 \mathrm{eV}$, respectively [20].

3.2. Structural Characterization. The XRD patterns of the undoped $\mathrm{ZnO}$ nanorods, $\mathrm{Zn}_{0.99} \mathrm{Fe}_{0.01} \mathrm{O}$ and $\mathrm{Zn}_{0.95} \mathrm{Fe}_{0.05} \mathrm{O}$ nanorods, are shown in Figure 4(a). The high diffraction peaks at 002 direction are an indication of the hexagonal wurtzite structure with single crystalline nature and they indicate that the Fe-doped $\mathrm{ZnO}$ nanorods grow along the $c$ axis of the $\mathrm{ZnO}$ consistent with the JCPDS number 36-1451 file. No evidence of any other secondary phase such as $\mathrm{FeO}$ or $\mathrm{Fe}_{3} \mathrm{O}_{4}$ has been observed. In Figure 4(b), we observed that the peaks position at 002 direction was shifted towards higher $2 \theta$ diffraction angle with the increasing of the Fe concentration and their full width at half maximum (FWHM) were also becomes larger while increasing the Fe concentration. The shift of the peaks positions and the relatively larger FWHM clearly indicated that the Fe ions replaced the $\mathrm{Zn}$ sites in the $\mathrm{ZnO}$ nanorods crystal matrix. These observations were also evident in similar samples grown by other techniques reported elsewhere $[10,11,14,17-20,24,25]$.

3.3. Magnetic Property. Superconducting quantum interference device (SQUID) measurements have been performed to investigate the room temperature ferromagnetic behavior of our Fe-doped $\mathrm{ZnO}$ nanorods samples. Figure 5 shows the magnetic hysteresis $(\mathrm{M}-\mathrm{H})$ curves measured from -10 

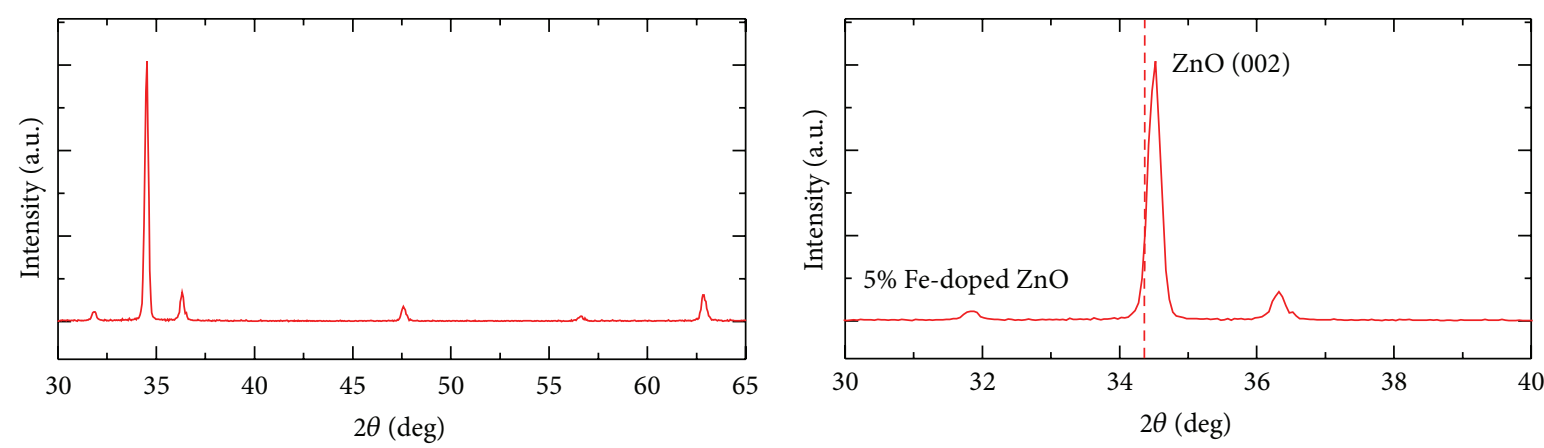

- $5 \%$ Fe-doped $\mathrm{ZnO}$
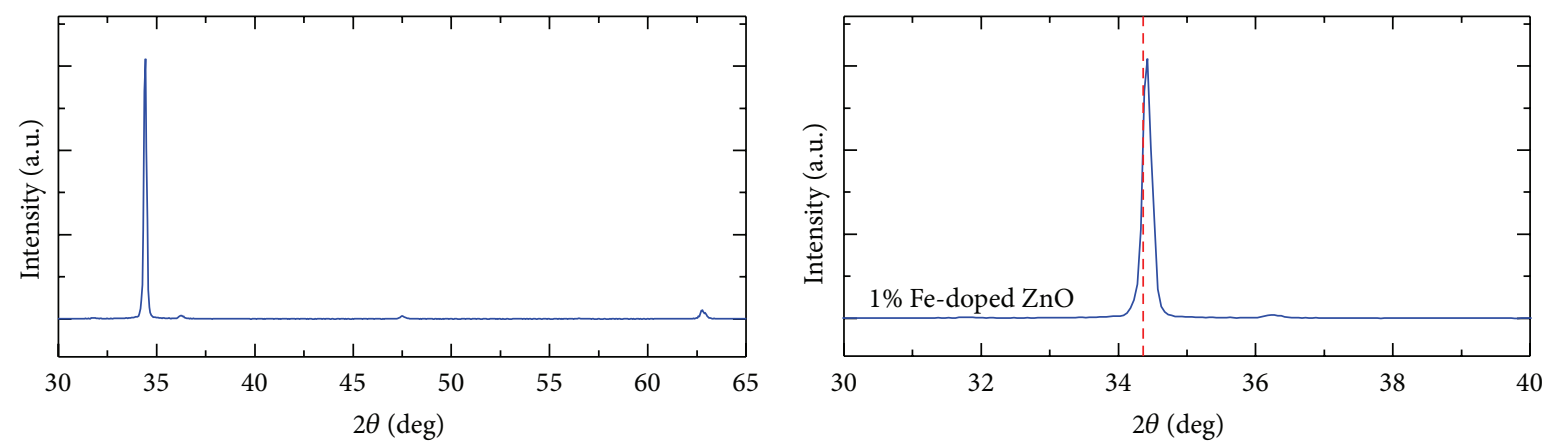

- $1 \%$ Fe-doped $\mathrm{ZnO}$
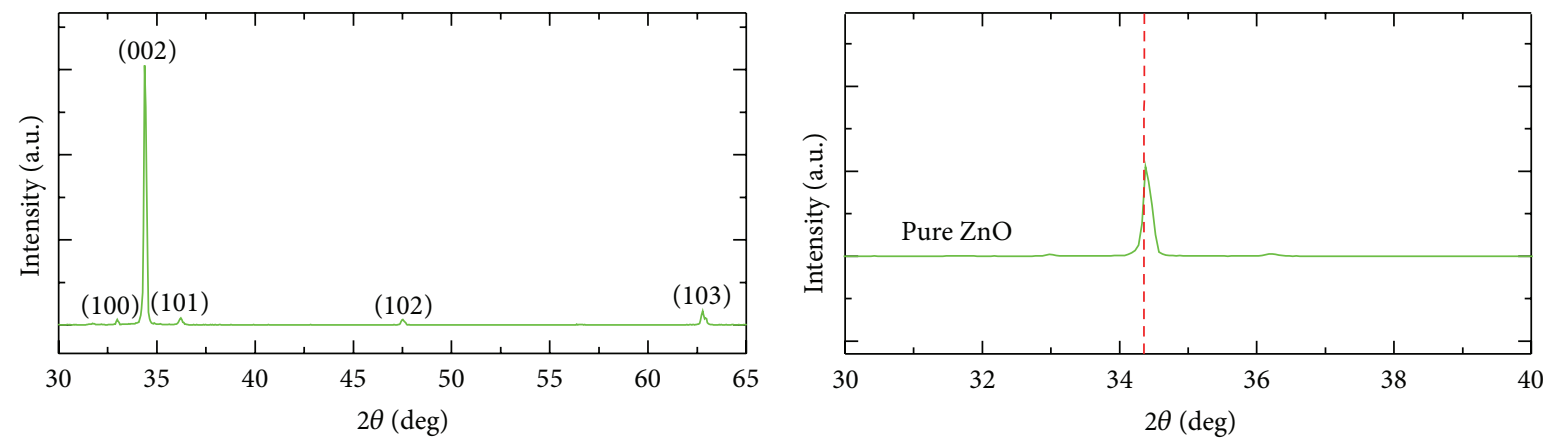

(a)

(b)

Figure 4: (a) The XRD patterns of undoped $\mathrm{ZnO}$ and Fe-doped $\mathrm{ZnO}$ nanorods; (b) the XRD patterns of Fe-doped $\mathrm{ZnO}$ at 002 peaks shifted to the higher $2 \theta$ values.

to $10 \mathrm{kOe}$ at $300 \mathrm{~K}$ of $\mathrm{Fe}$-doped $\mathrm{ZnO}$ samples. From these $\mathrm{M}-\mathrm{H}$ curves, the room temperature ferromagnetic hysteresis loops are clearly observed. According to theory, Fe-doped $\mathrm{ZnO}$ possesses ferromagnetic property at room temperature and the magnetic moments observed are due to the Fe $3 \mathrm{~d}$ orbitals and the observed magnetization value increases with the increase of the Fe concentration [15-17, 20, 22, 24, 25]. This supports our experimental results since we observed magnetic hysteresis at room temperature and the magnetization values observed increase from $2.5 \mu \mathrm{emu}$ to $9.1 \mu \mathrm{emu}$ for $\mathrm{Zn}_{0.99} \mathrm{Fe}_{0.01} \mathrm{O}$ and $\mathrm{Zn}_{0.95} \mathrm{Fe}_{0.05} \mathrm{O}$, respectively. This $\mathrm{M}-\mathrm{H}$ loop is higher than the results reported in [21, 36]. As we see from the EDX spectra, XPS spectra, and XRD patterns of our samples, it is clearly shown that there was not any other secondary phase of Fe or Fe oxides that has been observed. Therefore, the observed room temperature ferromagnetism in our Fe-doped $\mathrm{ZnO}$ nanorods originates from the Fe ions substituting the $\mathrm{Zn}$ ions in the $\mathrm{ZnO}$ nanorods matrix.

3.4. UV Sensor Based Au/Fe-Doped ZnO Schottky Diode. The $I-V$ characteristics for both the undoped $\mathrm{ZnO}$ and the Fedoped $\mathrm{ZnO}$ Schottky diodes were investigated under dark and UV illumination. Figure 6(a) shows $I-V$ characteristics of undoped $\mathrm{ZnO}$ and $\mathrm{Zn}_{0.95} \mathrm{Fe}_{0.05} \mathrm{O}$ Schottky diodes under dark. It was observed that both Schottky diodes have good rectifying characteristics. However, the $\mathrm{Au} / \mathrm{Zn}_{0.95} \mathrm{Fe}_{0.05} \mathrm{O}$ Schottky 


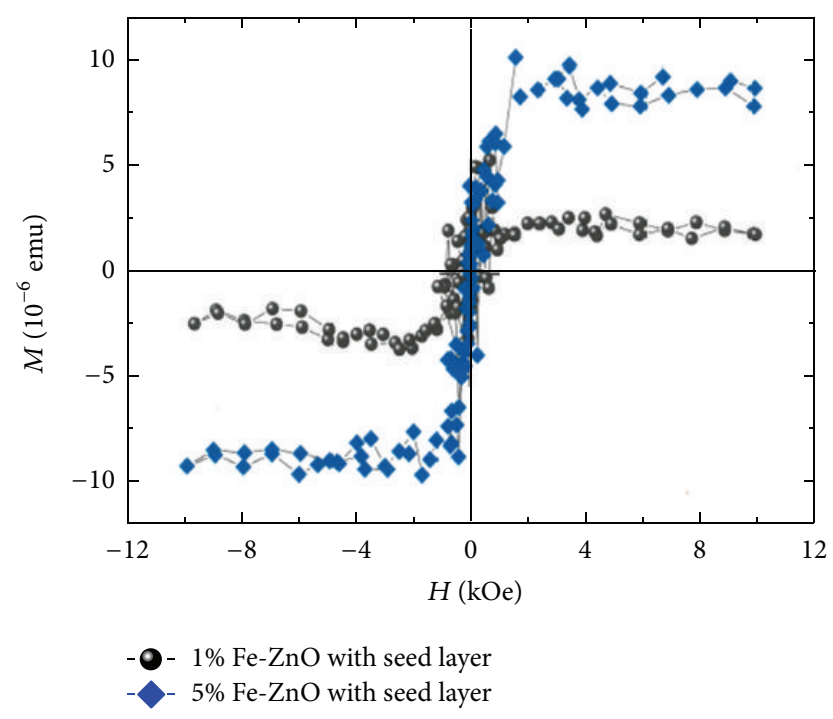

FIGURE 5: Room temperature ferromagnetic for Fe-doped $\mathrm{ZnO}$ nanorods.

diode has smaller leakage current, smaller turn on voltage with higher current at forward bias voltage than $\mathrm{Au} / \mathrm{ZnO}$ Schottky diode. Without UV illumination, the observed dark current was approximately $1.62 \mathrm{~mA}$ and $3.56 \mathrm{~mA}$ at bias of $5 \mathrm{~V}$ for the $\mathrm{Au} / \mathrm{ZnO}$ Schottky and the $\mathrm{Au} / \mathrm{Zn}_{0.95} \mathrm{Fe}_{0.05} \mathrm{O}$, respectively. This high dark current indicated that the Fe-doped $\mathrm{ZnO}$ nanorods have intrinsic donor defects which generates many free electrons and enhanced the dark conductance [37]. Figures 6(b) and 6(c) show the dark and UV illuminated $I$ $V$ characteristics of the $\mathrm{Au} / \mathrm{Zn}_{0.95} \mathrm{Fe}_{0.05} \mathrm{O}$ Schottky diode and $\mathrm{Au} / \mathrm{ZnO}$ Schottky diode, respectively. The responsivity $(R)$ of the photodetector is given by [38-41]

$$
R=\frac{I_{\mathrm{ph}}}{P_{\mathrm{inc}}}
$$

where $I_{\mathrm{ph}}=I_{\text {illuminated }}-I_{\text {dark }}$ is the photocurrent and $P_{\text {inc }}$ is the incident optical power at a given wavelength $(\lambda)$. The responsivity values calculated at $5 \mathrm{~V}$ forward bias are $0.60 \mathrm{~A} / \mathrm{W}$ for $\mathrm{Au} / \mathrm{ZnO}$ Schottky diode and $2.33 \mathrm{~A} / \mathrm{W}$ for $\mathrm{Au} / \mathrm{Zn}_{0.95} \mathrm{Fe}_{0.05} \mathrm{O}$ Schottky diode. The responsivity value of $\mathrm{Au} / \mathrm{Zn}_{0.95} \mathrm{Fe}_{0.05} \mathrm{O}$ is also higher than the commercial GaN UV detector $(0.1 \mathrm{~A} / \mathrm{W})$ and other photodetectors reported in [3843] and it is comparable to the UV photodetector reported [44]. The responsivity ratio between $\mathrm{Au} / \mathrm{Zn}_{0.95} \mathrm{Fe}_{0.05} \mathrm{O}$ Schottky diode and $\mathrm{Au} / \mathrm{ZnO}$ Schottky diode is equal to 3.9 and it is given by

$$
\text { Responsivity Ratio }=\frac{R_{\text {doped }}}{R_{\text {undoped }}},
$$

where $R_{\text {doped }}$ and $R_{\text {undoped }}$ are the responsivity of the $\mathrm{Au} / \mathrm{Zn}_{0.95} \mathrm{Fe}_{0.05} \mathrm{O}$ Schottky diode and $\mathrm{Au} / \mathrm{ZnO}$ Schottky diode, respectively. The device based $\mathrm{Au} / \mathrm{Zn}_{0.95} \mathrm{Fe}_{0.05} \mathrm{O}$ gives higher responsivity because when $\mathrm{Fe}$ ions incorporated into the $\mathrm{ZnO}$ latticeit acts as a donor which contributes to carriers and consequently improve its optical property, which possesses more electron-hole pairs generated under
UV excitation. Therefore, the incremental mobility of the $\mathrm{Zn}_{0.95} \mathrm{Fe}_{0.05} \mathrm{O}$ nanorods exhibits higher values compared to $\mathrm{ZnO}$ nanorods. Figures 6(d) and 6(e) show $5 \mathrm{~s}$ and $7 \mathrm{~s}$ of rising time response for $\mathrm{Au} / \mathrm{Zn}_{0.95} \mathrm{Fe}_{0.05} \mathrm{O}$ Schottky and $\mathrm{Au} / \mathrm{ZnO}$ Schottky diodes, respectively. While the decaying time is approximately $29 \mathrm{~s}$ for both devices, the rising time response is defined as the times required for the photocurrent reaching $63.3 \%$ of its saturated photocurrent and the decaying time response is refereed to $36.7 \%$ of its saturated photocurrent.

\section{Conclusion}

In summary, a series of high quality single crystalline of Fe-doped $\mathrm{ZnO}$ nanorods has been successfully synthesized using a modified hydrothermal method. A systematic study was performed to investigate the morphology and structural and magnetic properties of the $\mathrm{Fe}$-doped $\mathrm{ZnO}$ nanorods. Finally, the grown Fe-doped $\mathrm{ZnO}$ was used to fabricate high performance UV photodetector. SEM results show that the Fe-doped $\mathrm{ZnO}$ nanorods have hexagonal shapes and the EDX data revealed that the $\mathrm{Fe}$ peaks were presented in the $\mathrm{Fe}$-doped $\mathrm{ZnO}$ nanorods samples and the XPS results suggested that $\mathrm{Fe}^{3+}$ is incorporated into the $\mathrm{ZnO}$ lattice. The XRD analysis showed that by increasing the concentration of the $\mathrm{Fe}$ in the growth solution the 002 peak position and the FWHM were shifted to higher angle and become relatively larger, respectively. It is also shown that the $\mathrm{Fe}$ ions replaced $\mathrm{Zn}$ sites and were incorporated into the $\mathrm{ZnO}$ matrix with no secondary phases or clusters of $\mathrm{FeO}$ or $\mathrm{Fe}_{3} \mathrm{O}_{4}$ observed in the grown samples. The substitution of the $\mathrm{Fe}$ ions in the $\mathrm{ZnO}$ nanorods matrix significantly was manifested in a clear ferromagnetic behavior at room temperature $(300 \mathrm{~K})$ and the magnetization magnitude was observed to increase from $2.5 \mu \mathrm{emu}$ to $9.1 \mu \mathrm{emu}$ for $\mathrm{Zn}_{0.99} \mathrm{Fe}_{0.01} \mathrm{O}$ and $\mathrm{Zn}_{0.95} \mathrm{Fe}_{0.05} \mathrm{O}$, respectively. Moreover, the fabricated $\mathrm{Au} / \mathrm{Fe}-$ doped $\mathrm{ZnO}$ nanorods UV photodetector device achieved both high photoresponse and fast time response. Compared 


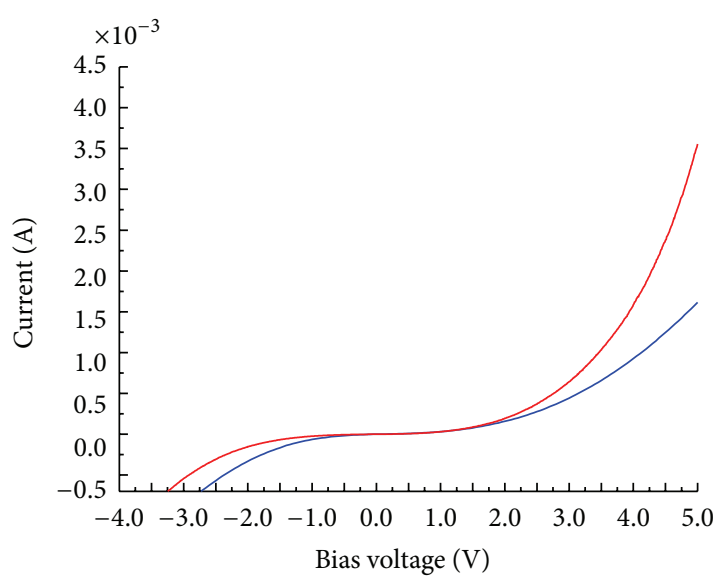

$I-V$ curve of Au/ZnO Schottky diode under dark $I$ - $V$ curve of $\mathrm{Au} / \mathrm{Fe}$-doped $\mathrm{ZnO}$ Schottky diode under dark

(a)

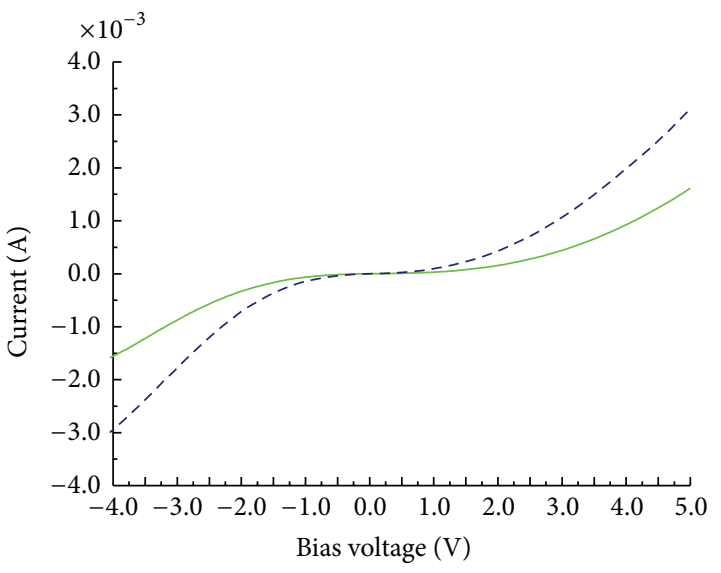

- I-V curve of $\mathrm{Au} / \mathrm{ZnO}$ Schottky diode under dark - - - I-V curve of $\mathrm{Au} / \mathrm{ZnO}$ Schottky diode $\mathrm{ZnO}$ under UV

(c)

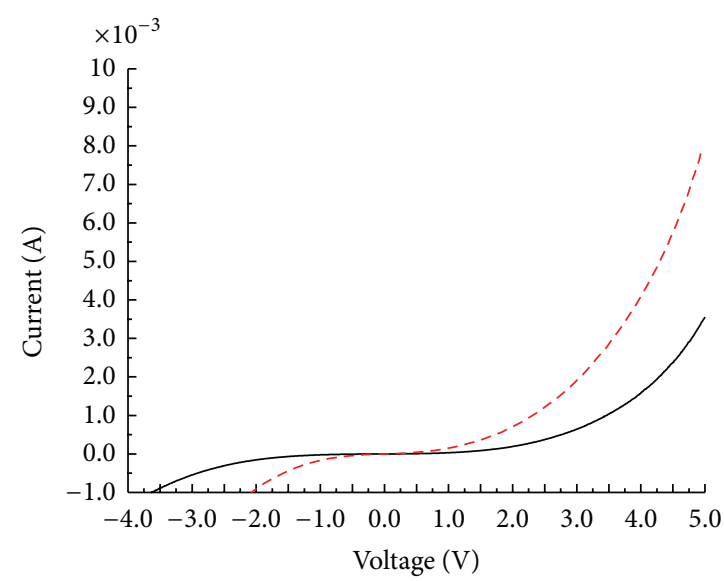

- I-V curve of $\mathrm{Au} / \mathrm{Fe}$-doped $\mathrm{ZnO}$ Schottky diode under dark - - I-V curve of Au/Fe-doped $\mathrm{ZnO}$ Schottky diode under UV

(b)

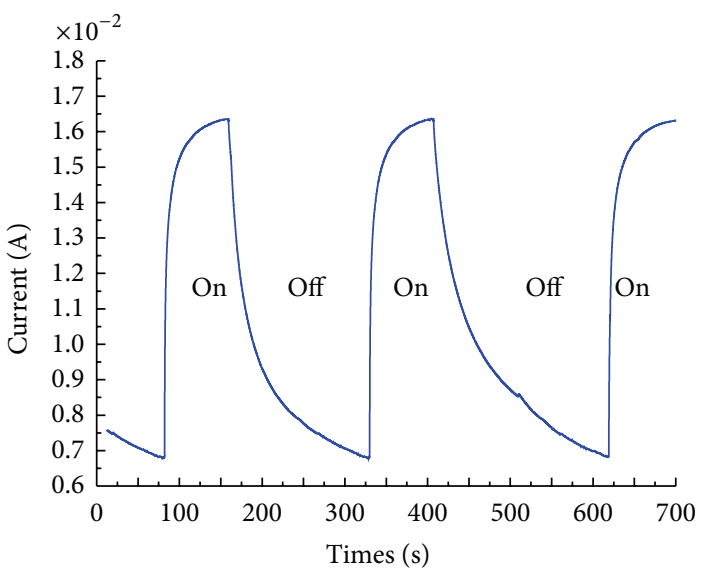

_ Time response of $\mathrm{Au} / \mathrm{Fe}$-doped $\mathrm{ZnO}$ Schottky diode

(d)

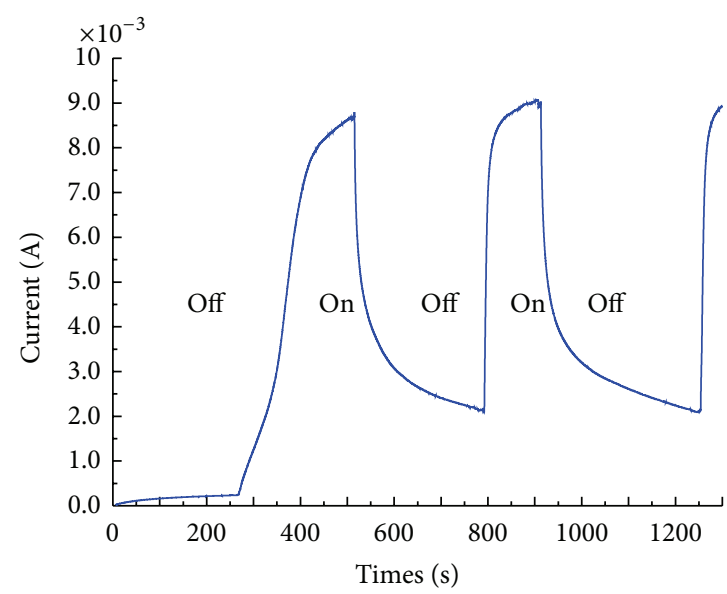

Time response of $\mathrm{Au} / \mathrm{ZnO}$ Schottky diode

(e)

Figure 6: (a) $I-V$ curves of $\mathrm{Au} / \mathrm{ZnO}$ and $\mathrm{Au} / \mathrm{Zn}_{0.95} \mathrm{Fe}_{0.05} \mathrm{O}$ Schottky diodes under dark; (b) $I-V$ characteristics of the $\mathrm{Au} / \mathrm{Zn}_{0.95} \mathrm{Fe}_{0.05} \mathrm{O}$ Schottky diode under dark and under UV illumination; (c) $I-V$ characteristics of the Au/ZnO Schottky diode under dark and under UV illumination; (d) time response of $\mathrm{Au} / \mathrm{Zn}_{0.95} \mathrm{Fe}_{0.05} \mathrm{O}$ Schottky diode; (e) time response of $\mathrm{Au} / \mathrm{ZnO}$ Schottky diode. 
to $\mathrm{Au} / \mathrm{ZnO}$ nanorods Schottky device, an improvement by a factor of 3.9 was achieved.

\section{Conflict of Interests}

The authors declare that there is no conflict of interests regarding the publication of this paper.

\section{Acknowledgment}

We wish to thank project grants from Carl Tryggers Stiftelsen, and Hero-M Vinnova center of Excellence at KTH. We wish also to thank ISP, Uppsala University.

\section{References}

[1] M. Snure, D. Kumar, and A. Tiwari, "Progress in Zno-based diluted magnetic semiconductors," JOM, vol. 61, no. 6, pp. 7275, 2009.

[2] T. Dietl, "Dilute magnetic semiconductors: functional ferromagnets," Nature Materials, vol. 2, pp. 646-648, 2003.

[3] S. J. Pearton, D. P. Norton, M. P. Ivill et al., "Ferromagnetism in transition-metal doped $\mathrm{ZnO}$," Journal of Electronic Materials, vol. 36, no. 4, pp. 462-471, 2007.

[4] K. R. Kittilstved, W. K. Liu, and D. R. Gamelin, "Electronic structure origins of polarity-dependent high- $T_{c}$ ferromagnetism in oxide-diluted magnetic semiconductors," Nature Materials, vol. 5, no. 4, pp. 291-297, 2006.

[5] C. Liu, F. Yun, and H. Morkoç, "Ferromagnetism of $\mathrm{ZnO}$ and GaN: a review," Journal of Materials Science: Materials in Electronics, vol. 16, no. 9, pp. 555-597, 2005.

[6] K. Ueda, H. Tabata, and T. Kawai, "Magnetic and electric properties of transition-metal-doped $\mathrm{ZnO}$ films," Applied Physics Letters, vol. 79, no. 7, pp. 988-990, 2001.

[7] P. Sharma, A. Gupta, K. V. Rao et al., "Ferromagnetism above room temperature in bulk and transparent thin films of Mndoped ZnO," Nature Materials, vol. 2, no. 10, pp. 673-677, 2003.

[8] Y. Lin, D. Jiang, F. Lin, W. Shi, and X. Ma, "Fe-doped ZnO magnetic semiconductor by mechanical alloying," Journal of Alloys and Compounds, vol. 436, no. 1-2, pp. 30-33, 2007.

[9] S. Gautam, S. Kumar, P. Thakur et al., "Electronic structure studies of Fe-doped $\mathrm{ZnO}$ nanorods by $\mathrm{x}$-ray absorption fine structure," Journal of Physics D: Applied Physics, vol. 42, no. 17, Article ID 175406, 2009.

[10] A. K. Mishra and D. Das, "Investigation on Fe-doped ZnO nanostructures prepared by a chemical route," Materials Science and Engineering B, vol. 171, no. 1-3, pp. 5-10, 2010.

[11] R. Saleh, S. P. Prakoso, and A. Fishli, "The influence of Fe doping on the structural, magnetic and optical properties of nanocrystalline $\mathrm{ZnO}$ particles," Journal of Magnetism and Magnetic Materials, vol. 324, no. 5, pp. 665-670, 2012.

[12] H. Çolak and O. Turkoglu, "Synthesis, crystal structural and electrical conductivity properties of fe-doped zinc oxide powders at high temperatures," Journal of Materials Science and Technology, vol. 28, no. 3, pp. 268-274, 2012.

[13] B. Ling, J. L. Zhao, X. W. Sun, S. T. Tan, Y. Yang, and Z. L. Dong, "Electroluminescence from ferromagnetic fe-doped $\mathrm{ZnO}$ nanorod arrays on p-Si," IEEE Transactions on Electron Devices, vol. 57, no. 8, pp. 1948-1952, 2010.
[14] A. J. Chen, X. M. Wu, Z. D. Sha, L. J. Zhuge, and Y. D. Meng, "Structure and photoluminescence properties of Fe-doped $\mathrm{ZnO}$ thin films," Journal of Physics D: Applied Physics, vol. 39, no. 22, pp. 4762-4765, 2006.

[15] L. M. Wang, J.-W. Liao, Z.-A. Peng, and J.-H. Lai, “Doping effects on the characteristics of Fe: $\mathrm{ZnO}$ films: valence transition and hopping transport," Journal of the Electrochemical Society, vol. 156, no. 2, pp. H138-H142, 2009.

[16] X. X. Wei, C. Song, K. W. Geng, F. Zeng, B. He, and F. Pan, "Local Fe structure and ferromagnetism in Fe-doped $\mathrm{ZnO}$ films," Journal of Physics Condensed Matter, vol. 18, no. 31, pp. 7471-7479, 2006.

[17] W. Cheng and X. Ma, "Structural, optical and magnetic properties of Fe-doped ZnO," Journal of Physics: Conference Series, vol. 152, no. 1, Article ID 012039, p. 7, 2009.

[18] A. G. Sobas, A. Galeckas, M. F. Sunding, S. Diplas, and A. Y. Kuznetsov, "An investigation of Fe-doped $\mathrm{ZnO}$ thin films grown by magnetron sputtering," Physica Scripta, vol. T141, Article ID 014004, 7 pages, 2010.

[19] J. T. Luo, Y. C. Yang, X. Y. Zhu, G. Chen, F. Zeng, and F. Pan, "Enhanced electromechanical response of Fe-doped $\mathrm{ZnO}$ films by modulating the chemical state and ionic size of the $\mathrm{Fe}$ dopant," Physical Review B, vol. 82, no. 1, Article ID 014116, 2010.

[20] W.-G. Zhang, B. Lu, L.-Q. Zhang et al., "Influence of preparation condition and doping concentration of Fe-doped $\mathrm{ZnO}$ thin films: oxygen-vacancy related room temperature ferromagnetism," Thin Solid Films, vol. 519, no. 19, pp. 6624-6628, 2011.

[21] G. Chen, J. J. Peng, C. Song, F. Zeng, and F. Pan, "Interplay between chemical state, electric properties, and ferromagnetism in Fe-doped ZnO films," Journal of Applied Physics, vol. 113, no. 10, Article ID 104503, 2013.

[22] H. Y. Yang, S. F. Yu, S. P. Lau, T. S. Herng, and M. Tanemura, "Ultraviolet Laser Action in Ferromagnetic $\mathrm{Zn}_{1-x} \mathrm{Fe}_{x} \mathrm{O}$ Nanoneedles," Nanoscale Research Letters, vol. 5, no. 1, pp. 247251, 2010.

[23] A. P. Rambu, V. Nica, and M. Dobromir, "Influence of Fedoping on the optical and electrical properties of $\mathrm{ZnO}$ films," Superlattices and Microstructures, vol. 59, pp. 87-96, 2013.

[24] C. Xia, C. Hu, Y. Tian, P. Chen, B. Wan, and J. Xu, "Roomtemperature ferromagnetic properties of $\mathrm{Fe}$-doped $\mathrm{ZnO}$ rod arrays," Solid State Sciences, vol. 13, no. 2, pp. 388-393, 2011.

[25] B. Panigrahy, M. Aslam, and D. Bahadur, "Effect of Fe doping concentration on optical and magnetic properties of $\mathrm{ZnO}$ nanorods," Nanotechnology, vol. 23, no. 11, Article ID 115601, 2012.

[26] C. W. Liu, S. J. Chang, C. H. Hsiao et al., "Diluted magnetic nanosemiconductor: Fe-Doped $\mathrm{ZnO}$ vertically aligned nanorod arrays grown by hydrothermal synthesis," IEEE Transactions on Nanotechnology, vol. 12, no. 4, pp. 649-655, 2013.

[27] S. Baek, J. Song, and S. Lim, "Improvement of the optical properties of $\mathrm{ZnO}$ nanorods by Fe doping," Physica B, vol. 399, no. 2, pp. 101-104, 2007.

[28] M. Willander, L. L. Yang, A. Wadeasa et al., "Zinc oxide nanowires: controlled low temperature growth and some electrochemical and optical nano-devices," Journal of Materials Chemistry, vol. 19, no. 7, pp. 1006-1018, 2009.

[29] G. Amin, M. H. Asif, A. Zainelabdin, S. Zaman, O. Nur, and $\mathrm{M}$. Willander, "Influence of $\mathrm{pH}$, precursor concentration, growth time, and temperature on the morphology of $\mathrm{ZnO}$ nanostructures grown by the hydrothermal method," Journal of Nanomaterials, vol. 2011, Article ID 269692, 9 pages, 2011. 
[30] X. L. Zhang, H. T. Dai, J. L. Zhao, S. G. Wang, and X. W. Sun, "Surface-morphology evolution of $\mathrm{ZnO}$ nanostructures grown by hydrothermal method," Crystal Research and Technology, vol. 49, no. 4, pp. 220-226, 2014.

[31] J.-H. Tian, J. Hu, S.-S. Li et al., "Improved seedless hydrothermal synthesis of dense and ultralong $\mathrm{ZnO}$ nanowires," Nanotechnology, vol. 22, no. 24, Article ID 245601, 2011.

[32] C. O. Chey, H. Alnoor, M. A. Abbasi, O. Nur, and M. Willander, "Fast synthesis, morphology transformation, structural and optical properties of $\mathrm{ZnO}$ nanorods grown by seed-free hydrothermal method," Physica Status Solidi A, 2014.

[33] L. J. Brillson and Y. Lu, "ZnO Schottky barriers and Ohmic contacts," Journal of Applied Physics, vol. 109, no. 12, Article ID 121301, p. 33, 2011.

[34] S. N. Das, J.-H. Choi, J. P. Kar, K.-J. Moon, T. I. Lee, and J.M. Myoung, "Junction properties of $\mathrm{Au} / \mathrm{ZnO}$ single nanowire Schottky diode," Applied Physics Letters, vol. 96, Article ID 092111, 2010.

[35] J. Rodríguez-Moreno, E. Navarrete-Astorga, R. Romero et al., "Electrochemically grown vertically aligned $\mathrm{ZnO}$ nanorod array $/ \mathrm{p}^{+}-\mathrm{Si}(100)$ heterojunction contact diodes," Thin Solid Films, vol. 548, pp. 235-240, 2013.

[36] A. Baranowska-Korczyc, A. Reszka, K. Sobczak et al., "Magnetic Fe doped $\mathrm{ZnO}$ nanofibers obtained by electrospinning," Journal of Sol-Gel Science and Technology, vol. 61, pp. 494-500, 2012.

[37] X. G. Zheng, Q. S. Li, J. P. Zhao et al., "Photoconductive ultraviolet detectors based on $\mathrm{ZnO}$ films," Applied Surface Science, vol. 253, no. 4, pp. 2264-2267, 2006.

[38] Z. Alaie, S. M. Nejad, and M. H. Yousefi, "Recent advances in ultraviolet photodetectors," Materials Science in Semiconductor Processing, 2014.

[39] N. H. Al-Hardan, A. Jalar, M. A. Abdul Hamid, L. K. Keng, N. M. Ahmed, and R. Shamsudin, "A wide-band UV photodiode based on $\mathrm{n}-\mathrm{ZnO} / \mathrm{p}-\mathrm{Si}$ heterojunctions," Sensors and Actuators, A: Physical, vol. 207, pp. 61-66, 2014.

[40] L. Luo, Y. Zhang, S. S. Mao, and L. Lin, "Fabrication and characterization of $\mathrm{ZnO}$ nanowires based UV photodiodes," Sensors and Actuators, A, vol. 127, no. 2, pp. 201-206, 2006.

[41] C. Periasamy and P. Chakrabarti, "Large-area and nanoscale $n$ $\mathrm{ZnO} / \mathrm{p}$-Si heterojunction photodetectors," Journal of Vacuum Science \& Technology B, vol. 29, no. 5, Article ID 051206, 2011.

[42] S. J. Young, L. W. Ji, T. H. Fang, S. J. Chang, Y. K. Su, and X. L. $\mathrm{Du}$, "ZnO ultraviolet photodiodes with Pd contact electrodes," Acta Materialia, vol. 55, no. 1, pp. 329-333, 2007.

[43] M. H. Mamat, Z. Khusaimi, M. Z. Musa, M. F. Malek, and M. Rusop, "Fabrication of ultraviolet photoconductive sensor using a novel aluminium-doped zinc oxide nanorod-nanoflake network thin film prepared via ultrasonic-assisted sol-gel and immersion methods," Sensors and Actuators A: Physical, vol. 171, no. 2, pp. 241-247, 2011.

[44] Z. Yang, M. Wang, X. Song, G. Yan, Y. Ding, and J. Bai, "High-performance $\mathrm{ZnO} / \mathrm{Ag}$ Nanowire/ZnO composite film UV photodetectors with large area and low operating voltage," Journal of Materials Chemistry C, vol. 2, no. 21, pp. 4312-4319, 2014. 

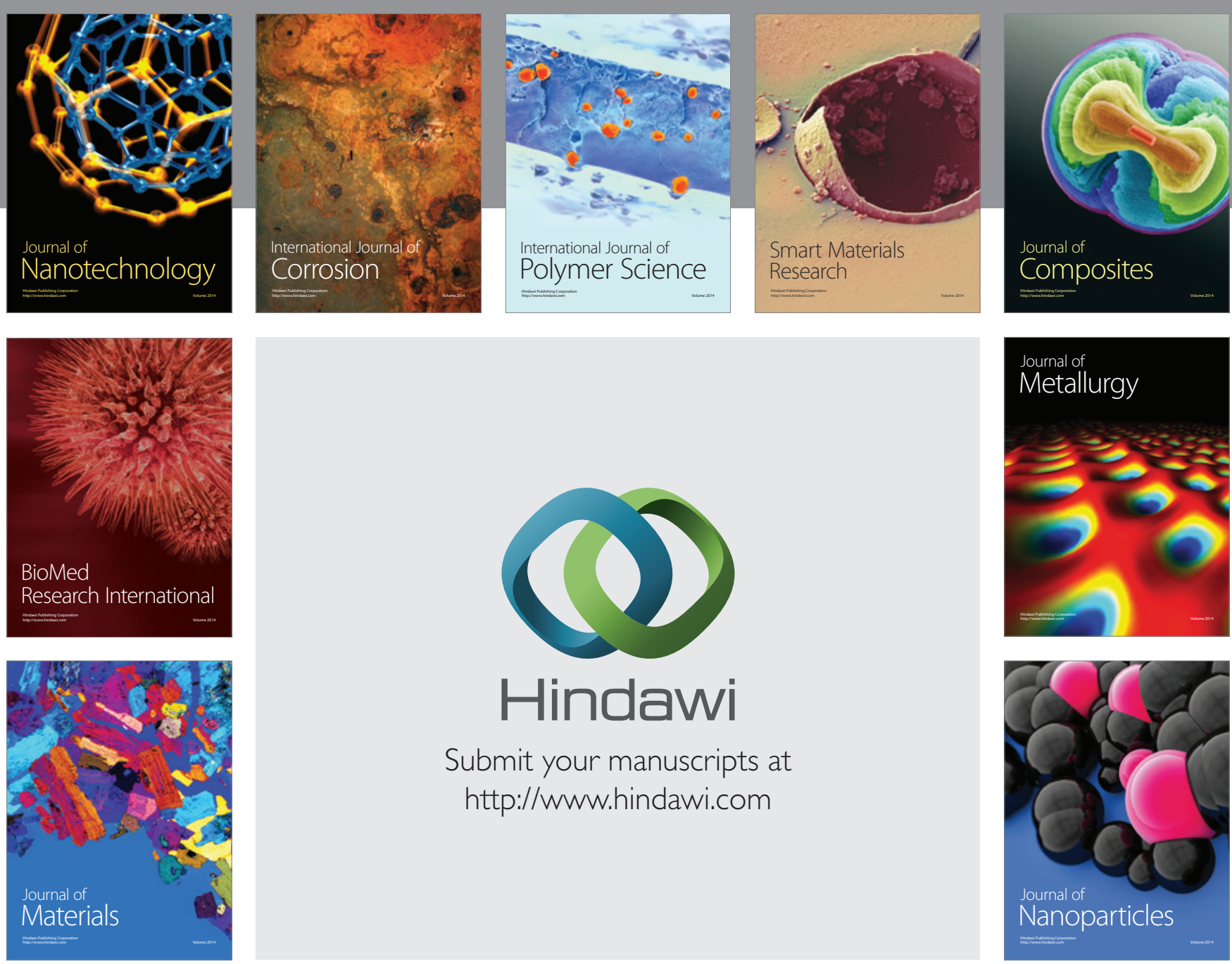

Submit your manuscripts at http://www.hindawi.com
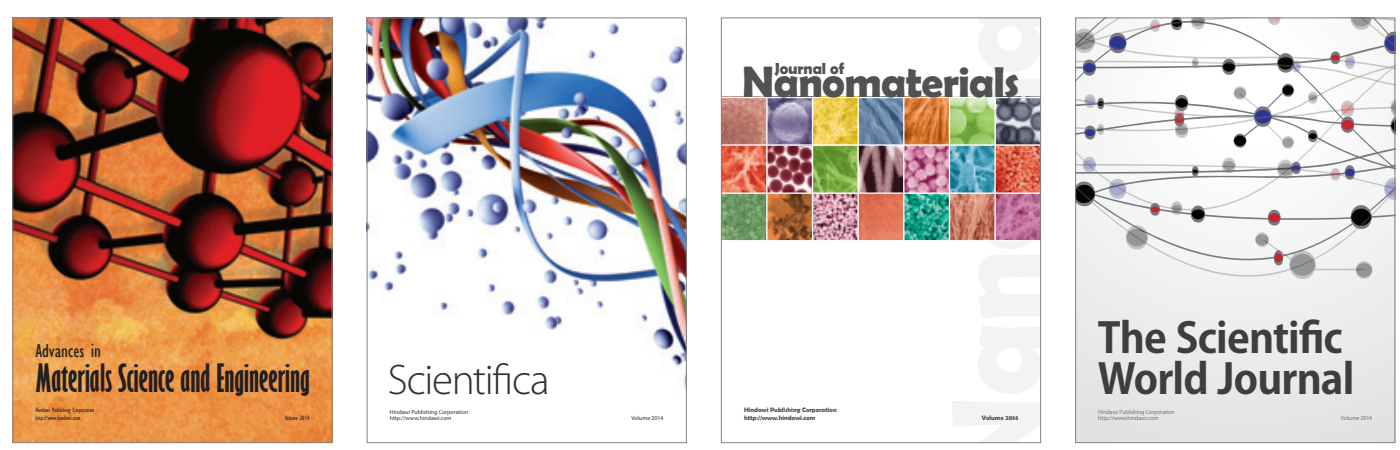

\section{The Scientific World Journal}
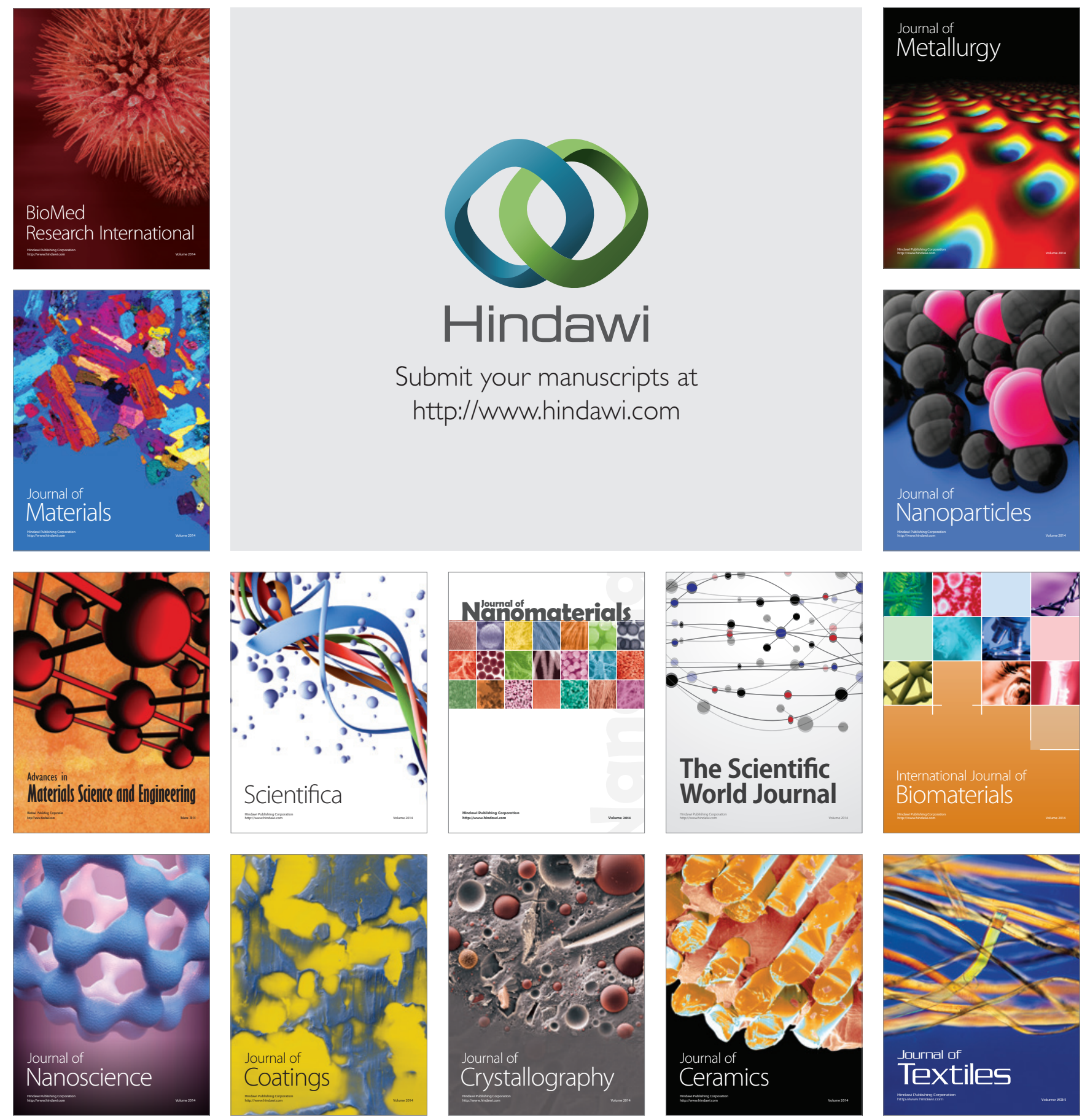